\title{
ELEMENTS OF THE S-GENE COMPLEX \\ III. CHROMOSOME FRAGMENTS AND NATURALLY OCCURRING S-GENE MUTATIONS IN NICOTIANA BONARIENSIS
}

\author{
KAMLA KANT PANDEY \\ Grasslands Division, D.S.I.R., Palmerston North, New Zealand
}

Received 16.ix.68

\section{INTRODUCTION}

Studies of spontaneous and X-ray induced mutations of the $S$ gene in two solanaceous species Petunia inflata (Brewbaker and Natrajan, 1960) and Nicotiana alata (Pandey, 1965, 1967a) showed that these mutations were usually associated with the presence of a $S$-bearing chromosome duplication in the genome. In an overwhelming proportion of these mutants, the duplication occurred as a free centric chromosome fragment, and was only rarely incorporated into the normal chromosome complement. Similar studies in Oenothera organensis (Onagraceae), Prunus avium (Rosaceae) (Lewis, 1951, 1954, 1961; Lewis and Crowe, 1954), Trifolium pratense and T. repens (Papilionaceae) (Pandey, 1956a), however, did not suggest the presence of any such duplication.

It has been proposed that the $S$-bearing fragment in $P$. inflata and $\mathcal{N}$. alata complements $S$-gene mutations which would otherwise be pollen lethal and, therefore, would not be recovered (Pandey, 1965). However, it is not known why some species should need $S$-bearing duplication for the viability of the $S$-gene mutant pollen while others apparently do not. In order to solve this problem additional species must be investigated for naturally occurring as well as induced $S$-gene mutations.

\section{S-GENE POLYMORPHISM AND NATURALLY OGGURRING MUTATIONS IN $\mathcal{N}$. bonariensis}

In a study of the breeding system and $S$-gene polymorphism in Nicotiana bonariensis (seed source-USDA, Beltsville, Maryland, U.S.A.) two of the twelve plants investigated in detail revealed a female-part mutation of the $S$ gene (Pandey, 1967b). A further study of the naturally occurring $S$-gene mutants (for techniques, see Pandey, 1967a,b) was then undertaken in fresh material of this species obtained from Professor D. R. Cameron, University of California, Berkeley, U.S.A. Of the 36 plants of this material studied, only 11 had normal male and female organs and were self-incompatible. Six plants were male-sterile but were normal for the female organ; two plants were female- as well as male-sterile. Seventeen plants were selfcompatible.

All plants were crossed as females with self-compatible $\mathcal{N}$. langsdorffi and the self-incompatible strain GM8 of $\mathcal{N}$. glauca for the study of $S$-gene polymorphism, and they were also intercrossed among themselves. The plants fell into three polymorphic classes, B (compatible with $\mathcal{N}$. langsdorffi, incompatible with $\mathcal{N}$. glauca GM8), G (compatible with both) and D (incompatible with both) (table l). The 11 normal, self-incompatible plants fell into three 


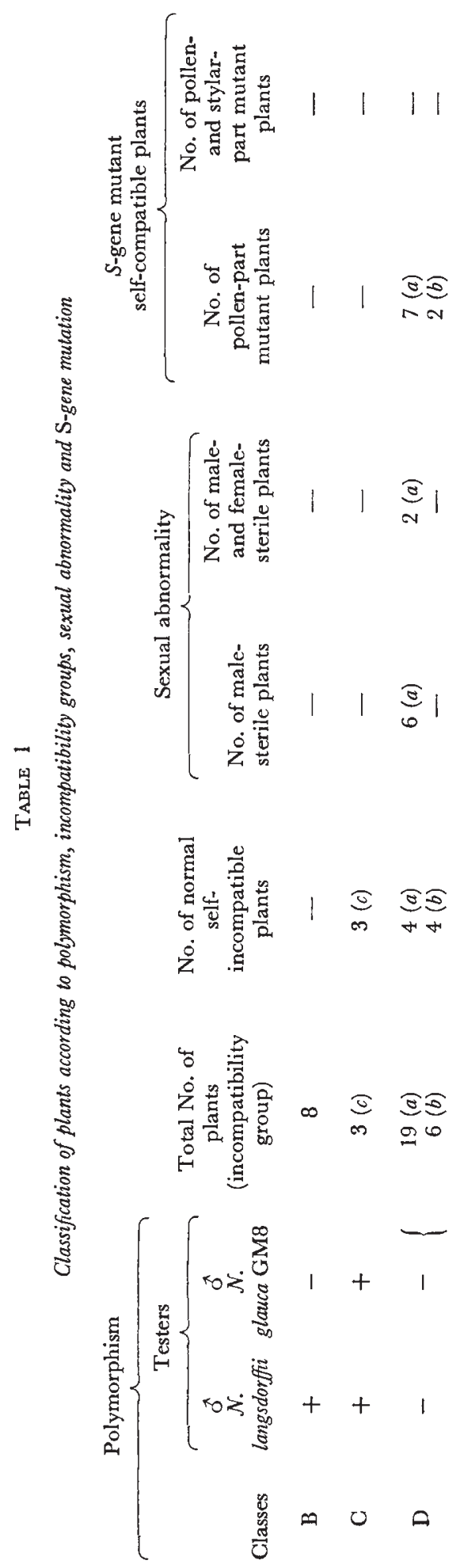


intra-incompatible and inter-compatible groups; two groups, $a$ and $b$, of four plants each, both belonging to the polymorphic class $D$; and a third group $(c)$ of three plants which was identical with class $C$. These plants were used as testers with the remaining plants, most of which could be classified into individual incompatibility groups on the basis of their pollentube reaction either as males or as females. All eight plants showing sexual abnormality, six male-sterile and two male- and female-sterile, belonged to the incompatibility group $a$. Plants of the same incompatibility group belonged to the same polymorphic class.

The data on $S$-gene polymorphism presented here, along with that on other species of Nicotiana, will be discussed in the next paper of this series. Here, only the cross-compatibility data of the 17 self-compatible plants will be examined in detail. Table 2 gives the results of crosses between the selfcompatible plants as females, and the 11 tester plants. Three kinds of plants were distinguished: (i) seven incompatible with the tester plants of group $a$, but compatible with those of groups $b$ and $c$; (ii) two incompatible with testers of group $b$ but compatible with those of groups $a$ and $c$; and (iii) eight compatible with all testers. In the reciprocal crosses, when self-compatible plants were used as male parents, all crosses, with the exception of a few involving two plants (13 and 19) of (iii), were compatible (total number of crosses, involving all three kinds of plants, were 47). These results showed that 9 of the 17 self-compatible plants had only male-part mutations of the incompatibility gene, with their female specificity remaining intact. Seven of these plants belonged to group $a$ and two plants to group $b$. The remaining eight plants, all belonging to polymorphic class $B$, could not be separated into incompatibility groups. Their distinct polymorphic class suggests that they belong to a fourth incompatibility group not represented by the normal form in this material. In two of these plants (13 and 19) the pollen behaviour was irregular. The cause of this is unknown.

Thus in $\mathcal{N}$. bonariensis there appear to be naturally occurring $S$-gene mutants of two kinds, affecting pollen-part alone and stylar-part alone (Pandey, 1967b).

Chromosome studies at meiosis of $15 S$-gene mutant plants, seven plants with pollen-part and eight plants with complete mutation, revealed only the normal nine pairs of chromosomes, none of the plants showing an extra centric fragment (table 2 and plate I, figs. 1-9). The only unusual feature observed was the presence of a rather high number of univalents at MI (plate I, figs. 2-7). The nature of orientation of the univalents suggested that this was due to earlier terminalisation of chiasmata in the smaller pairs of chromosomes rather than to a lack of synapsis. It may be noted that in the extensive cytological work done on Nicotiana (Goodspeed, 1954), the only case where the presence of a relatively large number of univalents at $\mathrm{MI}$ is believed to be genetically controlled has been found in an $F_{1}$ hybrid involving $\mathcal{N}$. bonariensis, $\mathcal{N}$. bonariensis $\times \mathcal{N}$. longiflora. Another point worth noting is that the maximum number of univalents is six, thus leaving six normally behaving bivalents, which is the presumed original number of chromosomes in the family Solanaceae.

\section{3. $S$-gene mutations, and Duplication of the $S$ Locus}

The presence of naturally occurring $S$-gene mutants without a centric fragment in $\mathcal{N}$. bonariensis contrasts sharply with the occurrence of fragments 
క్

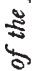

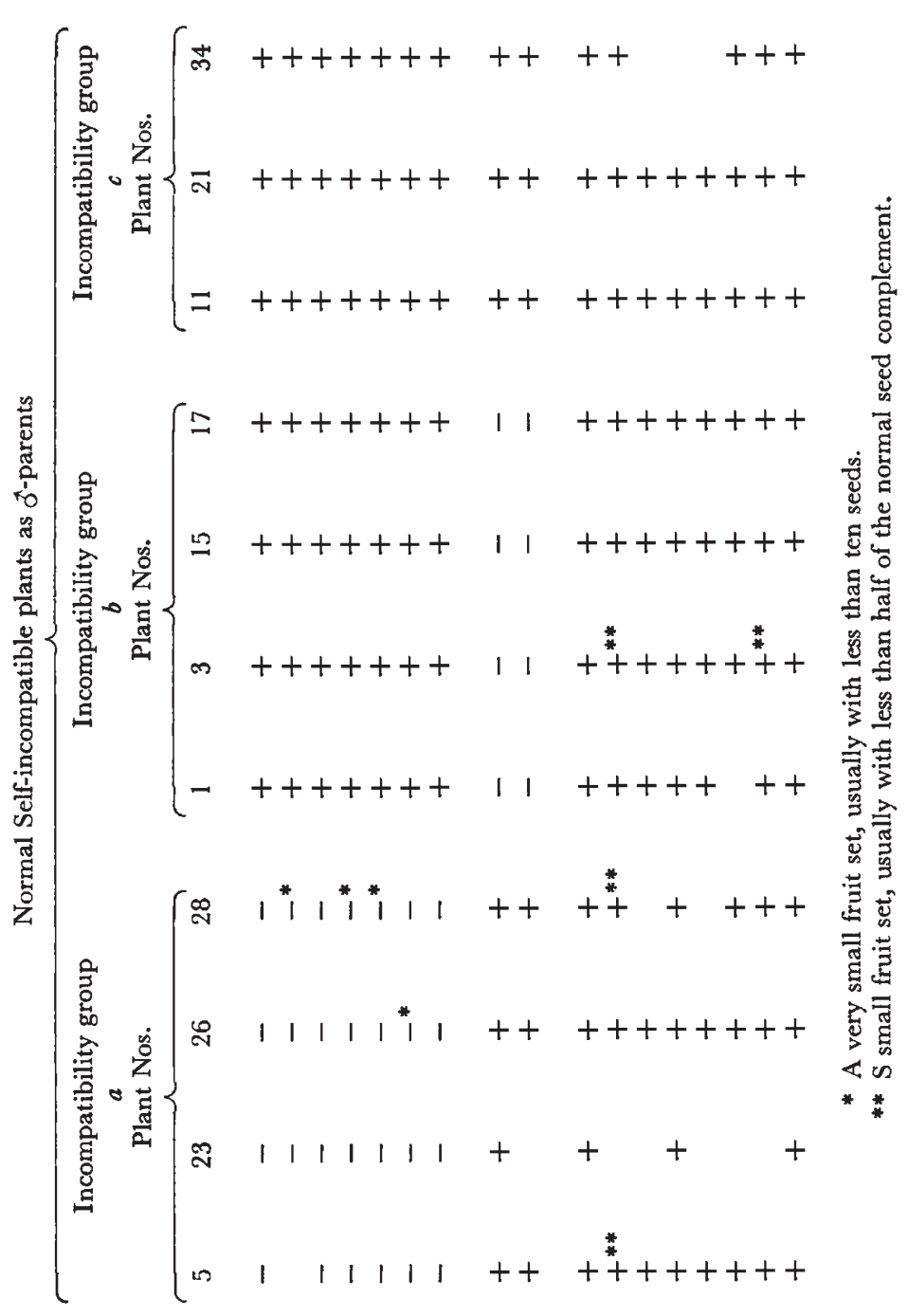


in the overwhelming proportion of induced $S$-gene mutants in the sister species $\mathcal{N}$. alata. This difference cannot be attributed to the violent action of the X-rays on the nuclear material, since both of the spontaneous mutants in $\mathcal{N}$. alata also had centric fragments. The difference, therefore, appears to be species specific, and although at this stage it cannot be certain, it seems likely that even induced-mutations of $\mathcal{N}$. bonariensis would not require an $S$-bearing duplication for the viability of the $S$-gene mutant pollen. Of the six species studied so far for the $S$-gene mutation, only two, $P$. inflata (Brewbaker and Natrajan, 1960) and $\mathcal{N}$. alata (Pandey, 1965), seem to require $S$-gene duplication in the genome for the survival of the mutant pollen, while four others, $O$. organensis, $P$. avium (Lewis, 1954), $T$. pratense and $T$. repens (Pandey, 1956a) have no such requirement. Furthermore, none of these species has shown a difference in the nature of mutations between those produced spontaneously and those produced through the aid of X-rays. There are, however, two alternatives which must be considered. One possibility is that in nature the presence of the fragment is transitory, lasting only till the mutant $S$ locus in the genome recovers the essential element from the duplicated locus on the fragment through crossing-over during meiotic pairing between the $S$-bearing normal chromosome and the fragment. Such pairing has been seen to occur in $\mathcal{N}$. alata (Pandey, 1967a). This seems highly unlikely, for it would involve the assumption that all of the two kinds of $S$-gene mutants found in $\mathcal{N}$. bonariensis had gone through this process successfully, whereas no such clear-cut case has been found in the selfed and crossed generation plants of the mutants in $P$. inflata and $\mathcal{N}$. alata. The other possibility is that the duplication bearing a fully functional $S$ allele is incorporated in the normal genome, and the self-compatibility is due to competitive interaction. This is completely ruled out for stylar-part mutations and, in view of the extremely rare occurrence of this situation in $\mathcal{N}$. alata and $P$. inflata, it is difficult to believe that this would be the case in all the seven pollen-part mutant plants examined in $\mathcal{N}$. bonariensis.

The question now is: What accounts for this species difference? Assuming that $S$-gene duplication in the nucleus is usually a necessary prerequisite for the survival of $S$-gene mutants in the pollen, and considering the wide occurrence of $S$-gene polymorphism in nature revealed by studies in the genus Nicotiana (Pandey, 1967b, 1968, and unpublished results), it is possible that many of the apparently diploid species have one or more duplications of the $S$ locus hidden in their genome. T. repens is a good example in this connection. Although chromosomally a tetraploid species, cytologically and genetically (at least from the standpoint of $S$ alleles) it behaves as a normal diploid species, having a perfectly functional one-locus gametophytic system of incompatibility (Atwood, 1940). In this species the duplicate $S$ locus has lost, presumably, its element(s) controlling allelic specificity, but not necessarily its other elements, for example those controlling the viability of the gametes (Lewis, 1954; Pandey, 1956a). A similar situation probably occurs in $T$. medium, a highly polyploid species having variable chromosome numbers ranging from 78 to 80 in Canada, 82 in New Zealand, to 126-30 in Scandinavia (Fejer, 1967). In spite of its high degree of polyploidy this species is still fully self-incompatible (Fejer, 1967) - a condition most likely to occur only if most of the duplicate $S$ loci in the genome have lost, at least, their allelic specificity controlling intraspecific incompatibility. The ability of the duplicate $S$ locus, which has lost its $S$-allelic specificity, to complement 
partly or fully the mutant $S$ allele would depend largely on the extent of its own degeneration.

Of the three investigated diploid species of Solanaceae, $P$. inflata has $2 n=14$, and $\mathcal{N}$. alata and $\mathcal{N}$. bonariensis have $2 n=18$ chromosomes (Darlington and Wylie, 1955). Although there is a large number of species with the chromosome number of $2 n=24$, the basic number in this family appears to be six, and not twelve (Goodspeed, 1954; Löve and Löve, 1961). This is suggested from the experimental number $2 n=12$ in the genera Capsicum (Christensen and Bamford, 1943), Datura (Satina et al., 1941), Lycopersicon (Rick, 1945) and Nicotiana (Webber, 1933). Thus it is possible that there has been a duplication of the $S$-bearing chromosome early in the evolution of this family, a conclusion which also is consistent with the finding of twolocus systems of incompatibility in certain species of the two genera, Physalis (Pandey, 1957) and Solanum (Pandey, 1960, 1962).

Duplication of the $S$ locus, similar to that described above in Solanaceae, is also possible in the families Onagraceae, Papilionaceae, and Rosaceae. Onagraceae has the basic number of five chromosomes whereas $O$. organensis, the species investigated, has $n=7$. The lowest basic number in the tribe Trifolieae (and four other tribes) is six (the lowest number for the family Papilionaceae is five, occurring in two tribes), whereas $T$. pratense and $T$. repens, the two species investigated, have $n=7$ and $n=16$ respectively. The lowest basic number for the family Rosaceae, $n=7$, occurs in the large genus Rosa and 17 other genera, whereas $P$. avium, the species investigated, has $n=8$ (Darlington and Wylie, 1955).

The duplication of the $S$-bearing chromosome in the incipient species must have broken down the self-incompatibility through competitive interaction (Lewis, 1947; Pandey, 1956b). The restoration of the one-locus self-incompatibility in most of the species would then have occurred through the loss of the allelic specificity in the duplicate $S$ locus (Pandey, 1960). This deficiency in the $S$ complex could have come about either singly, leaving the other elements of the complex unimpaired, or jointly in association with various other elements, in which case some other functions of the $S$ complex would also have been lost along with the specificity. In $P$. inflata and $\mathcal{N}$. alata, where mutations are associated with the presence of fragments (Brewbaker and Natrajan, 1960; Pandey, 1965), the ability of the duplicate locus to complement the $S$-allele mutants appears to have been seriously impaired, while in $\mathcal{N}$. bonariensis, where mutants have no fragments, this ability appears to remain relatively intact. In $O$. organensis, $P$. avium and $T$. pratense it appears to have been only partly impaired since mutations affecting either the pollenpart or stylar-part, but never both parts simultaneously, do occur without a duplicate fragment (Lewis, 1954, 1961 ; Pandey, 1956a). In the tetraploid T. repens, which probably has more than one duplication in the genome all three types of mutations are recovered without fragments (Pandey, $1956 a, 1965)$. Thus on the above hypothesis the ability to produce $S$-allele mutants with or without $S$-bearing fragments would vary from species to species, depending upon its evolutionary history.

A deficiency in a duplicate locus may affect its ability to complement one class of mutants without undermining its ability to complement others. For example, it is possible that most deficiencies in the duplicate loci affect their ability to complement mutants of the specific deletion type, obtained in our induced-mutation studies (Lewis, 1960; Pandey, 1967a). They do not, 
however, necessarily affect their ability to complement mutants of the type which give rise to different specificities, such as that involved in the $S$-gene polymorphism determining interspecific incompatibility, or that involved in the origin of new self-incompatibility alleles determining intraspecific incompatibility. It is suggested here that the evolution of the large scale $S$-gene polymorphism determining intra- and interspecific incompatibility may be a consequence of the incorporation of one or more $S$-gene duplications in the genome early in the history of the various phylogenetic branches of angiosperms.

The potential versatility of the breeding system conferred on plants having the incorporation of one or more duplicate $S$ loci in the genome is immense. The complementation effects of natural $S$-gene duplication may have been of far greater significance in the evolution of flowering plants than is considered at present.

\section{Summary}

1. Seventeen of the 36 plants of Nicotiana bonariensis grown from the one seed source were self-compatible. Six plants were male-sterile and two were male- and female-sterile. Eleven of the plants were perfectly normal and self-incompatible.

2. Appropriate testing of the self-compatible plants revealed that they were all $S$-gene mutants. Nine were pollen-part mutants.

3. Cytological examination at meiosis of 15 ( 7 pollen-part and 8 complete) of the $S$-gene mutants showed that they all had the normal chromosome complement $(2 n=18)$, and none had centric fragments. This contrasts sharply with the induced $S$-allele mutants in the sister species $\mathcal{N}$. alata which, along with those of $P$. inflata, have been found to be associated usually with the presence of an $S$-bearing centric chromosome fragment.

4. It has been suggested that a large number of species of flowering plants have one or more $S$-gene duplications incorporated in their normal genome. These duplicate $S$ loci have usually all lost their $S$-allele specificity and, to varying degrees in different species, certain other essential elements of the complex, thus affecting their ability to complement the new $S$-gene mutants.

5 . The role of the presumed, natural $S$-gene duplications in the evolution of $S$-gene polymorphism is briefly discussed.

Acknowledgments.-I am indebted to Professor D. R. Cameron, University of California Berkeley, U.S.A., for providing the seed material, and to Dr L. Corkill, Director, for facilities and encouragement during the course of this study. Thanks are also due to Miss A. Laxton for technical assistance.

\section{REFERENGES}

ATwood, s. s. 1940. Genetics of cross-incompatibility among self-incompatible plants of Trifolium repens. 7. Amer. Soc. Agron., 32, 955-968.

BREWBAKer, J. L., AND NATRAJAN, A. T. 1960. Centric fragments and pollen-part mutation of incompatibility alleles in Petunia. Genetics, 45, 699-704.

CHRISTENSEN, H. M., AND BAMFORD, R. 1943. Haploids in twin seedlings of pepper, Capsicum annuum L. 7. Hered., 34, 99-104.

DARlington, C. D., ANo WYlie, A. P. 1955. Chromosome Atlas of Flowering Plants. George Allen \& Unwin, London.

FEJER, s. O. 1967. Diallel crosses in Trifolium medium. Can. J. Genet. Cytol., 9, 799-804. 
goodspeed, T. H. 1954. The Genus Nicotiana. Chronica Botanica Company, Walthum, Mass.

LEWIS, D. 1947. Competition and dominance of incompatibility alleles in diploid pollen. Heredity, 1, 85-108.

LEWIS, D. 1951. Structure of the incompatibility gene. III. Types of spontaneous and induced mutation. Heredity, 5, 399-414.

LEWIs, D. 1954. Comparative incompatibility in angiosperms and fungi. Adv. Genet., 6, 235-285.

LEWIs, D. 1960. Genetic control of specificity and activity of the $S$ antigen in plants. Proc. Roy. Soc., B, 151, 468-477.

LEWIS, D. 1961. Chromosome fragments and mutation of the incompatibility gene. Nature, $190,990-991$.

LEWIS, D., AND GROWE, L. K. 1954. Structure of the incompatibility gene. IV. Types of mutation in Prunus avium L. Heredity, 8, 357-363.

LÖVE, A., AND LÖVE, D. 1961. Chromosome numbers of central and northwest European plant species. Opera Bot., 5, 1-581.

PANDEY, K. K. 1956a. Mutations of self-incompatibility alleles in Trifolium pratense and T. repens. Genetics, 41, 327-343.

PANDEY, K. K. 1956b. Incompatibility in autotetraploid Trifolium pratense. Genetics, 41, 353-366.

PANDEY, K. K. 1957. Genetics of self-incompatibility in Physalis ixocarpa Brot.-A new system. Am. F. Bot., 44, 879-887.

PANDEY, K. K. 1960. Self-incompatibility in two Mexican species of Solanum. Nature, 185, 483-484.

PANDEY, K. K. 1962. Genetics of incompatibility behaviour in the Mexican Solanum species, S. pinnatisectum. Zeit.f. Vererbung., 93, 378-388.

PANDEY, K. K. 1965. Centric chromosome fragments and pollen-part mutation of the incompatibility gene in Nicotiana alata. Nature, 206, 792-795.

PANDEY, K. K. 1967a. Elements of the $S$-gene Complex. II. Mutation and complementation at the $S_{\Upsilon}$ locus in Nicotiana alata. Heredity, 22, 255-284.

Pandey, K. K. 1967b. S-gene polymorphism in Nicotiana. Genet. Res., Camb., 10, 251-259.

PANDEY, к. K. 1968. Compatibility relationships in flowering plants: Role of the $S$ gene complex. Amer. Nat., 102, 475-489.

RICK, C. M. 1945. A survey of cytogenetic causes of unfruitfulness in the tomato. Genetics, 30, $347-362$.

SATINA, S., BERGNER, A. D., AND BLAKEsLEe, A. F. 1941. Morphological differentiation in chromosomes of Datura stramonium. Amer. F. Bot., 28, 383-390.

webrer, J. M. 1933. Cytological features of Nicotiana glutinosa haploids. 7. Agr. Res., 47, $845-867$ 


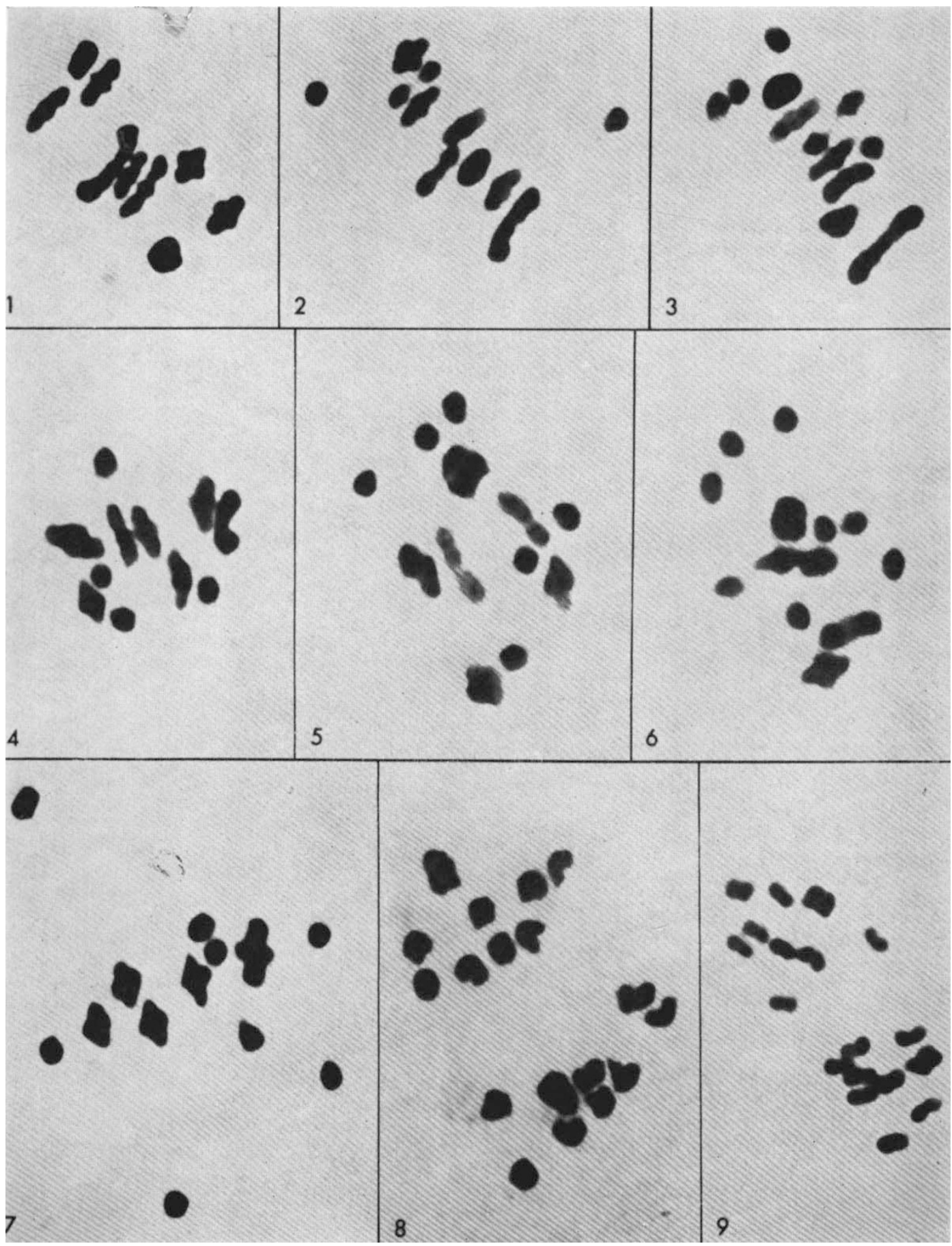

Meiotic cells of $\mathcal{N}$. bonariensis mutants. $\times 2350$

FIG. 1.-Normal MI cell showing no univalents, in the pollen-part mutant 9503-29.

FIGs. 2 and 3.-MI cells showing two univalents in each, in the mutant 9503-19.

FIG. 4.-MI cell showing four univalents, in the mutant 9503-32.

FIG. 5.-MI cell showing six univalents, in the mutant 9503-13.

FIGs. 6 and 7.--MI cells showing six univalents in each, in the mutant 9503-32.

FIG. 8. - Normal AI in the pollen-part mutant 9503-29.

FIG. 9. - Normal AI in the mutant 9503-32. 